\title{
PERSPECTIVA CONSTITUCIONAL SOBRE O NÃO RECONHECIMENTO DA NACIONALIDADE ITALIANA PARA OS DESCENDENTES DE TIROLESES NO BRASIL
}

\section{RESUMO}

Fernanda Analu Marcolla ${ }^{1}$ Alejandro Knaesel Arrabal ${ }^{2}$

O presente artigo pretende analisar quais fatores impedem que os brasileiros descendentes de tiroleses obtenham o reconhecimento da nacionalidade italiana. Em decorrência da divisão territorial do Tirol entre os países da Itália e da Áustria, os cidadãos tiroleses que habitavam aquela localidade deveriam se manifestar para o governo local sobre qual nacionalidade optariam. Devido a guerra e aos problemas socioeconômicos nos países supracitados, muitos tiroleses em busca de uma condição de vida melhor migraram para o Brasil sem realizar a escolha ou sendo obrigados a renunciar a nacionalidade de origem, sendo este, um empecilho para a concessão da nacionalidade italiana.

PALAVRAS-CHAVE: Apátridas; Imigração; Itália; Nacionalidade; Tiroleses.

\section{CONSTITUTIONAL PERSPECTIVE ON THE FAILURE OF RECOGNITION OF THE ITALIAN NATIONALITY FOR THE DESCENDANTS OF TYROLES IN BRAZIL}

\begin{abstract}
This article aims to analyze which factors prevent Brazilians of Tyrolean descent from obtaining recognition of Italian nationality. As a result of the territorial division of Tyrol between the countries of Italy and Austria, Tyrolean citizens who inhabited that locality had to manifest themselves to the local government about which nationality they would choose. Due to the war and socioeconomic problems in the aforementioned countries, many Tyroleans in search of a better living condition migrated to Brazil without making the choice or being forced to renounce their nationality of origin, which is an obstacle to the granting of Italian nationality.
\end{abstract}

KEYWORDS: Stateless; Immigration; Italy; Nationality; Tyroleans.

\footnotetext{
${ }^{1}$ Mestranda em Direito Público pelo Programa de Pós-Graduação em Direito da Universidade Regional de Blumenau (FURB). Especialista em Direitos Humanos e Direito Constitucional pela Universidade de Direito de Coimbra/PT. Especialista em Direito Penal e Direito Processual Penal pela Universidade Damásio de Jesus. Bacharel em Direito pelo Centro Universitário de Brusque (UNIFEBE). Advogada inscrita na OAB/SC $\mathrm{n}^{\circ}$. 53.746. Membro da Comissão Criminal da OAB/SC da Subseção de Brusque. Endereço eletrônico: f.marcolla@furb.br.

${ }^{2}$ Doutor em Direito Público pelo Programa de Pós-Graduação em Direito da Universidade do Vale dos Sinos UNISINOS. Mestre em Ciências Jurídicas pela Universidade do Vale do Itajaí - UNIVALI. Especialista em Direito Administrativo pela Universidade Regional de Blumenau - FURB. Professor e pesquisador dos Programas de Mestrado em Direito (PPGD) e Administração (PPGAd) da FURB. Líder do grupo de pesquisa Direito, Tecnologia e Inovação - DTIn (CNPQ-FURB). Membro dos grupos de pesquisa Constitucionalismo, Cooperação e Internacionalização - CONSTINTER (CNPq-FURB) e Estado, Sociedade e Relações Jurídicas Contemporâneas (CNPq-FURB), com estudos em direito de propriedade intelectual, desenvolvimento tecnológico e inovação. Membro da AGIT - Agência de Inovação Tecnológica da Universidade Regional de Blumenau-(FURB). E-mail: arrabal@ furb.br.
} 


\section{INTRODUÇÃO}

O Brasil possui uma população multicultural em decorrência da própria colonização portuguesa, assim como a multiculturalidade é favorecida em razão de políticas públicas de imigração com países como Itália, Áustria, Alemanha, Holanda e Espanha.

Com o final da Primeira Guerra Mundial, o Brasil recebeu muitos imigrantes advindos principalmente da Itália e da Alemanha. Em busca de melhores condições de vida, estes imigrantes acabavam por renunciar sua pátria de origem.

Segundo Bertonha (2001, p. 17), o Brasil recebeu cerca de um milhão e duzentos mil imigrantes italianos entre os anos de 1890 a 1920. Estas pessoas chegaram ao Brasil muitas vezes sem nacionalidade definida, ou ainda, haviam renunciado a nacionalidade originária para poder emigrar para a América.

Muitos foram os casos de imigrantes que se denominaram italianos ao chegarem ao Brasil, mas eram nacionais do território até então austro-húngaro. Deste modo, não se pode afirmar com propriedade a procedência territorial dos imigrantes tiroleses e trentinos.

A complexidade de investigar a nacionalidade originária dos habitantes da região do Tirol do Sul se deve ao fato de conflitos territoriais. A região supracitada pertenceu por certo período ao império Austríaco e, com a assinatura do tratado de Saint-Germain e a unificação da Itália em 1861, a região do Tirol passou ao domínio italiano.

Considerando estes fatores, o presente trabalho procura revelar as condições pelas quais não se reconhece o direito a nacionalidade italiana aos descendentes dos italianos trentinos e tiroleses advindos do Império Austro-Húngaro.

Desenvolvido a partir de revisão bibliográfica e normativa, o estudo contempla duas partes. A primeira explora critérios históricos em relação a vinda de imigrantes italianos para o Brasil. O segundo destaca as condicionantes para o reconhecimento da nacionalidade italiana aos descendentes de italianos tiroleses e trentinos. 


\section{IDENTIDADE CULTURAL NO CONTEXTO DA EMIGRAÇÃO}

A emigração está interligada ao avanço da globalização, sendo este um fenômeno que rapidamente se transformou em um "encantamento" da modernidade, que, segundo Baumann, (2021, p. 7) "é capaz de abrir as portas de todos os mistérios presentes e futuros" ou ainda, segundo Arrabal (2017, p. 4), "representa um projeto de hegemonia social e econômica".

A humanidade, na sua própria complexidade existencial, tende a buscar meios alternativos de sobrevivência, mesmo que para isso sejam necessárias significativas rupturas culturais. Neste contexto, afirma Morin (2011, p. 69) que "a consciência da complexidade nos faz compreender que jamais poderemos escapar da incerteza e que jamais poderemos ter um saber total".

Destaca-se que a nação brasileira é marcada por percalços variados a fim de compreender a sua identidade cultural. Isso se deve pela diversidade de imigrantes que o Brasil recebeu ao longo de sua colonização. Entre os anos de 1820 a 1924 o continente americano recebeu mais de 40 milhões de europeus (COSTA, 2008, p. 106).

Segundo Bertonha (2001, p. 17), o Brasil recebeu em torno de um milhão e meio de imigrantes que se identificavam como italianos. No entanto, a grande maioria não tinha conhecimento da divisão territorial entre a Itália e a Áustria, o que dificultou o reconhecimento do pertencimento originário.

Neste sentido é necessário compreender o pertencimento cultural como produto dos modos de constituição de identidades. Segundo Costa (2008, p. 117):

[...] as identidades culturais são formas provisórias e contingentes de articulação de uma determinada posicionalidade circunstancial no bojo de uma relação particular. Isto é, a identidade individual e do grupo não é prépolítica, mas sim definida a partir das informações e possibilidades de reconhecimento comunicadas pelo entorno social, em um momento determinado e diante de uma situação específica.

A importância da identificação cultural se deve ao fato de poder preservar a cultura ancestral de uma comunidade ou região. De fato, muitos italianos que pertenciam ao Tirol da Áustria, tinham como idioma oficial além do italiano, o alemão e o ladino, fator este que gerava certa discriminação cultural por parte da população italiana que tinha somente a língua originária como idioma oficial (ALTMAYER, 2020). 
Segundo Costa $(2008,116$.) os países tendem a desenvolver um conjunto histórico de valores e formas de vida que constituem uma identidade nacional, entre eles, um dos mais importantes é o idioma oficial de uma nação:

O elemento mais visível desse substrato cultural correspondente à nação seria o idioma comum a ser reconhecido por todos os que desejam fazer parte da nação ou residir no âmbito dos limites territoriais do Estado-nação em questão. A justificativa para a importância da aquisição do idioma no caso da campanha de nacionalização é meramente simbólico-afetiva, isto é, esquecer o idioma de origem representaria a prova da adesão e sua lealdade à nova pátria.

Para o supracitado autor, a campanha de nacionalização realizada no Brasil trouxe como consequência a renúncia da cultura originária dos imigrantes, assim como da própria identidade cultural, haja vista que estes precisaram aderir a cultura e os costumes de sua nova pátria.

Conforme será melhor destacado a seguir, os tiroleses e trentinos, antes de emigrarem do seu país de origem para o Brasil, acabaram não optando por uma nacionalidade quando foram questionados pelo governo local sobre qual país se identificavam e queriam pertencer (FRAGA, KEGEL, 2011, p. 133).

Deste modo, até os dias atuais se discute os motivos do não reconhecimento da nacionalidade italiana aos descendentes destes imigrantes, embora o entendimento da doutrina majoritária reconheça ter havido a renúncia da identidade nacional original com a emigração para o Brasil.

\section{BREVE HISTÓRICO SOBRE A IMIGRAÇÃO TIROLESA}

Para melhor compreendimento do assunto aqui abordado, se faz necessário um breve resumo da situação geográfica do Tirol do Sul, o qual está localizado na região alpina, hoje dividida entre Áustria e Itália.

Historicamente a região do Tirol sofreu alterações quanto ao seu pertencimento. No século XV até 1813 a região pertencia ao domínio Austríaco. Posteriormente passou a integrar o Império Austro-húngaro, até 1918. Por fim, após a Primeira Guerra Mundial (1918), a metade sul da região foi ocupada pela Itália (ALTMAYER, 2008). 
Enquanto domínio da Áustria, o Tirol era dividido em três grandes regiões, denominadas Tirol do Norte, Tirol do Leste e Tirol do Sul, sendo esta última o motivo de desavenças geográficas e políticas aqui estudadas. Segundo Altmayer (2008), o Tirol do Sul ${ }^{3}$ era composto pelas seguintes cidades tirolesas:

[...] Innsbruck, Kufstein, Landeck, Schwaz e Lienz no Tirol austríaco; Bolzano (Bozen), Brixen (Bressanone), Meran (Merano), Trento (Trient), Rovereto (Rofreit) e Borgo Valsugana na Região Trentino-Südtirol (Itália) e Cortina d'Ampezzo na Província de Belluno (Itália).

Com o fim do principado de Trento em 1803, e em decorrência das invasões napoleônicas, o Império da Áustria assumiu a administração dos principados eclesiásticos sob sua tutela: Trento, Bressanone, Salzburgo, entre outros. No entanto, administração dos territórios supracitados, após a queda de Napoleão e com o Congresso de Viena de 1815, passam para o governo do Condado do Tirol, cujo conde era o próprio imperador austríaco (ALTMAYER, 2020).

A Itália por sua vez, somente foi unificada e reconhecida como um país em 1861, sendo um Estado/Nação com muitas dificuldades socioeconômicas e com poucos territórios iniciais. Destaca-se que nesta época a região do Tirol era pertencente à Áustria, vindo a ser integralizada em território italiano em momento histórico posterior. Sobre a unificação da Itália é importante ressaltar que:

[...] foi um dos últimos países da Europa a se unificar; a Unificação foi um processo histórico complexo, que começou oficialmente a partir do dia em que foi proclamado o Regno d'Italia, isto é, 17 de março de 1861, e se concluiu em 20 de setembro de 1870. [...] Aqui, é bom esclarecer que as palavras "Itália", "italianos" e similares são realmente usadas desde o tempo dos romanos, mas como um conceito geográfico, isto é, relativo à península itálica e algumas ilhas próximas. No caso da cidadania, o uso dessas palavras tem que ter rigor técnico, uma base legal. Repetindo, tecnicamente, a Itália como país nasce apenas em 17 de março de 1861 (MANTESSO; FERREIRA; ZANINI, 2018, p. 38).

A região do Tirol do Sul, a qual incorpora o Trentino Alto Edige, pertenceu ao Império Austro-Húngaro, e somente após o fim da Primeira Guerra Mundial foi anexada oficialmente ao território Italiano com a assinatura do tratado de Saint-Germain em 16 de julho de 1920. (MANTESSO; FERREIRA; ZANINI, 2018, p. 44).

\footnotetext{
${ }^{3}$ Antes de ser dividida, a região que hoje forma o Tirol do Sul e o Trentino eram unificadas na região Tirol do Sul (Südtirol, Sudtirolo).
} 
Desta feita, as pessoas nascidas no Tirol antes de 1920 pertenciam ao império Austro-Húngaro, sendo cidadãos Austríacos e não Italianos. Segundo Campos (2018, p. 363), por mais que a lei não seja capaz de constituir uma sociedade, ela pode gerar nos indivíduos a percepção de pertencer a uma comunidade devido a sua própria cultura:

A lei (e o estado) não constitui a sociedade. Contudo, ela atribui a esse complexo de vivência identitária o condão da legitimação. Saber-se amparado pela lei gera nos indivíduos a percepção de pertencimento não só a uma comunidade, mas a uma nação constitucionalmente arranjada e autenticada.

Quanto a percepção de "pertencer" a uma cultura, neste caso a Austríaca ou Italiana, na época em que a região do Tirol do Sul passou a integrar o território italiano, as pessoas que residiam naquela localidade foram obrigadas a optar por uma das nacionalidades. Deste modo, os nativos deveriam se auto identificar culturalmente para o governo local, reafirmando sua nacionalidade italiana ou alterando sua residência para a Áustria e continuar como cidadão austríaco.

Segundo Altmayer (2018, p. 10) a cultura trentina e a cultura tirolesa são complementares pela própria história, não podendo ser consideradas autônomas:

[...] a cultura da região trentina é a cultura tirolesa em língua italiana. A cultura tirolesa é aquela dos Alpes centrais e se assemelha àquela do Sul da Alemanha, da Suíça e da região alpina do Vêneto, no Norte da Itália. Os hábitos, o folclore, os trajes típicos, a arte popular, os hábitos religiosos (e as festas religiosas), a culinária e a musicalidade são as mesmas em todas as áreas tirolesas. Existem diferenças e tradições regionais, próprias a cada vale, mas trazem as características do contexto cultural alpino, do qual a região do Tirol (Tirol-Südtirol-Trentino) faz parte.

No entanto, em decorrência da fervorosa cultura religiosa cristã na época, muitos cidadãos do Tirol acabaram optando pela identidade austríaca devido a serem reconhecidos como mais católicos que os italianos, e também pelo fato do Papa ter excomungado o reino italiano enquanto o Imperador da Áustria, Francisco José I, era visto como um defensor da fé católica:

A identidade dos trentinos era baseada na religião católica e no culto ao Imperador da Áustria, Francisco José I. A Itália, em 1870, conquistou militarmente Roma e outros territórios da Igreja, por isso o Papa excomungou o reino italiano, considerando-o um Estado ateu. A ÁustriaHungria defendia a Igreja e o Papa, em vista disso os trentinos, como eram católicos fervorosos, preferiam ser súditos austríacos a pertencer ao Reino da Itália, um Estado condenado pelo Pontífice. Muitos trentinos que imigraram 
para o Brasil traziam consigo um quadro com a imagem de Francisco José devido ao culto ao imperador, e, por causa disso, vários deles transferiram sua simpatia deste para Dom Pedro II (GROSSELLI, 1999). O imperador austríaco era visto como um defensor da fé católica pelo fato de apoiar as causas da Igreja Católica (CORRÊA, 2018, p. 1).

Segundo Dalbosco (2016), um dos motivos para a Itália ter interesse em agregar em seu território o Tirol, era devido ao fato que aquela região poderia ser utilizada como uma "fronteira natural" em decorrência de suas cadeias montanhosas que dividiam o Norte e o Sul do Tirol:

Assim sendo, a divisão do Tirol foi acordada em termos militares, desrespeitando a vontade do povo tirolês, que no curso das sangrentas batalhas da Primeira Guerra, lutou bravamente - e com sucesso - para conservar a unidade da própria terra. No entanto, tendo o Império Austríaco saído da guerra derrotado, o antigo Condado do Tirol se viu dividido entre dois países.

Como já mencionado, o território Austríaco era composto na época por 3 regiões, quais sejam; Tirol do Norte, Tirol do Leste e Tirol do Sul. Destas, as duas primeiras possuíam como idioma a língua exclusivamente alemã, enquanto a terceira, possuía o idioma alemão, italiano e ladino (DALBOSCO, 2016).

De fato, a região do Tirol do Sul apresentava características culturais mistas. Assim, grupos políticos da época questionavam seu pertencimento a Áustria em decorrência da população falar o idioma Italiano:

Os nacionalismos causaram inúmeros conflitos ao longo do século 19 e culminaram na Primeira e na Segunda Guerras Mundiais. No pensamento dos nacionalistas, não havia espaço para regiões mistas, de fronteira, como era o caso do Tirol, cuja população fala alemão, italiano e ladino, cada qual com seus respectivos dialetos locais. Muito dessa argumentação redutiva procura justificar a pertença do território sul-tirolês ao estado italiano ou, ainda, serve para o discurso "anti-autonomista" de certos grupos políticos italianos. São argumentos do tipo "Em Trento sempre se falou italiano e, por isso, eles não podiam ser cidadãos austríacos", "os tiroleses são de língua alemã e os trentinos de língua italiana", "o principado de Trento era uma terra de língua italiana e não fazia parte da região do Tirol" etc. (ALTMAYER, 2020).

Com o término da primeira grande guerra, a Província de Trento foi formalmente anexada ao reino da Itália, através do Tratado de paz de Saint German, sendo que este tratado determinou que todos os habitantes daquela região teriam prazo de 10 anos para regularizar sua nacionalidade:

\section{Revista Brasileira de Direito Internacional | e-ISSN: 2526-0219 | Encontro Virtual |}

v. 7 | n. 2 | p. 01 - 15 | Jul/Dez. 2021. 
[...] todos os habitantes da antiga monarquia austro-húngara teriam direito à nacionalidade do país que dominava o respectivo território antes pertencente ao império. Em outras palavras, os habitantes das províncias de Trento e Bolzano teriam direito à nacionalidade italiana, pois a partir de então esses territórios estavam anexados ao reino italiano. O prazo para requerer a nacionalidade do país em que se encontrasse o território anexado era de um ano 10, a partir da entrada em vigor do Tratado de Saint-Germain (FRAGA, KEGEL, 2011, p. 133).

No entanto, por mais que se possa compreender que os cidadãos da região do Tirol tiveram a opção por escolher por uma "nacionalidade italiana ou austríaca" no momento em que a região foi anexada à Itália, muitas pessoas destas localidades emigraram, com destino ao Brasil, sem que tivessem optado por uma nacionalidade.

Segundo Fraga e Kegel (2011, p. 133), após a o término da primeira guerra “os descendentes de imigrantes trentinos ficaram sem o referencial nacional europeu, afinal, o Império austro-húngaro, de onde eles haviam emigrado já não mais existia, e tampouco puderam optar pela nacionalidade italiana”.

O próprio governo austríaco não amparou as reivindicações dos tiroleses trentinos que demonstravam interesse em emigrar da região, como ato contrário à saída dos cidadãos tiroleses, o governo desaconselhava a emigração e procurava impedi-la por meios legais:

Cumpre também registrar o fato de que o império Austro-Húngaro exigia que, os súditos que decidissem emigrar deveriam renunciar a cidadania austríaca. As motivações para tal atitude daquele império eram tanto políticas, visando barrar o crescente número de pessoas que decidiam partir para a América, como de ordem econômica, visando retirar do império toda a responsabilidade pelos súditos emigrantes (FRAGA, KEGEL, 2011, p. 133).

Afirma Corrêa $(2014$, p. 2) que o governo austríaco retirava a cidadania austríaca dos cidadãos que emigrassem para a América, adicionando uma observação desta decisão em seus passaportes:

No passaporte do imigrante Giacomo Costamilan, imigrado com sua família do Trentino para a Colônia Caxias em 1878, há a seguinte declaração: "confirma-se que o aqui denominado declarou que se desvincula do privilégio da cidadania austríaca, e que emigra para a América, pelo que a partir deste momento deixa de ser cidadão austríaco".

Os trentinos que chegavam ao Brasil eram considerados "tiroleses" ou "austríacos", pois assim era descritos na lista de chegada de imigrantes (CORRÊA, 2014, p. 2). Entretanto, 
em decorrência do idioma, muitos trentinos foram listados como italianos ou alemães ao chegarem no Brasil, o que impossibilita até hoje a identificação da região de procedência:

Naquela época, os trentinos entravam no Brasil com passaporte austríaco e eram chamados de tiroleses ou austríacos, porque sua região de origem Trentino Alto Ádige - estava sob o domínio do Império Austro-Húngaro. Ao optarem pela saída do Tirol italiano ou do Trentino, recebiam o passaporte e tinham que declararem-se não mais pertencentes a essa comunidade, perdendo seus direitos de súditos do Império. Eram informados de que não receberiam nenhuma ajuda do Governo para a solução de seus problemas.

A busca pela preservação da história dos emigrantes tiroleses, inclusive pela complexidade de sua nacionalidade é um fundamento legitimador, quanto a memória, em diversas de suas dimensões (coletiva, histórica, oficial, etc.), a qual virá à tona como recurso de homogeneização de uma identidade coletiva (CAMPOS, 2018, p. 360).

Entre os anos de 1890 e 1920 o Brasil recebeu cerca de um milhão e duzentos mil imigrantes considerados italianos, os quais se deslocaram para residir nos estados de São Paulo, Paraná, Santa Catarina e Rio Grande do Sul (BERTONHA, 2001, p. 17).

A complexidade do estudo da nacionalidade dos tiroleses se deve ao grande fluxo migratório de italianos para o Brasil, sem que houvesse o devido reconhecimento da procedência territorial deste povo, ou ainda, em muitos casos, ao fato de terem sido obrigados a renunciarem a sua identidade de origem em decorrência de perseguição política.

\section{FORMAS DE RECONHECIMENTO DA NACIONALIDADE: ANÁLISE DO CASO DOS TIROLESES}

A nacionalidade é um direito fundamental garantido no art. $15^{\circ}$ da Declaração Universal dos Direitos do Humanos, o qual dispõe que "1. Todo o indivíduo tem direito a ter uma nacionalidade. 2. Ninguém pode ser arbitrariamente privado da sua nacionalidade nem do direito de mudar de nacionalidade" (DUDH, 1948).

Para Maués (2013, p. 649), a nacionalidade confere aos habitantes de um local o amplo direito de proteção estatal, entre eles a cidadania no tocante a participação ativa na vida política:

Esse novo contexto demanda a definição de critérios para saber quem integra a comunidade política. Durante a Revolução Francesa, as propostas que 
enfatizavam a "virtude cívica", caracterizando a cidadania como participação ativa na vida política, foram sendo abandonadas com a derrota dos jacobinos. Em lugar da decisão à coisa pública, o critério adotado para definir o cidadão será o da nacionalidade.

Sendo a nacionalidade considerada um direito humano, cabe ao indivíduo que emigrou de seu país de origem buscar formas legais de adquirir a nacionalidade secundária ou ainda de eleição (MAZZOULI, 2012, p. 692).

É necessário destacar o conceito de Acquaviva (2000, p. 35) quanto a nacionalidade:

[...] nacionalidade é vínculo meramente jurídico, pertinente a direitos civis, em razão do local de nascimento ou ascendência paterna (nacionalidade originária), ou, ainda de manifestação de vontade do próprio interessado (nacionalidade secundária, obtida mediante naturalização.

No tocante a nacionalidade originária, segundo Guerra (2015, p. 362) existe três formas para seu reconhecimento:

a) Jus Soli: Chamado de direito do solo, é o critério segundo o qual é concedida a nacionalidade do Estado em que a pessoa nasceu. Tal critério foi adotado por países que buscavam o povoamento de seu território, visando criar um vínculo permanente com os novos integrantes de seu povo. Tal modelo prepondera entre os países norte-americanos.

b) Jus Sanguinis: É o direito de sangue, segundo o qual o indivíduo adquire a nacionalidade de seus genitores, independentemente de seu lugar de nascimento. É um critério adotado por países europeus como a Itália, com acentuada emigração, propiciando que os descendentes nascidos em outros países continuem ligados à pátria de seus genitores, facilitando a sua integração.

c) Sistema misto: Tal sistema é uma junção do sistema jus soli e jus sanguinis. Esse é o caso do Brasil, que apesar de a princípio se filiar ao jus soli, adota também características do jus sanguinis. (Sem grifo no original)

Cabe observar, que nos casos supracitados não há exigência de pertencimento à uma comunidade étnica como condição de nacionalidade, haja vista que "mesmo na hipótese de jus sanguinis, o que a determina não é o sangue do indivíduo, mas a qualidade de membro da comunidade política reconhecida a seus pais, que podem ou não ter laços biológicos com o grupo" (MAUÉS, 2013, p. 648).

Desta feita, considera-se nacionalidade originária, mesmo que em grau variado, o lugar do nascimento, denominado pela doutrina como jus soli, ou da nacionalidade dos pais, a qual é denominada como jus sanguinis. No entanto, segundo Resek (2018, p. 140), em algumas situações a manifestação da vontade é pressuposto indispensável para requerimento da nacionalidade ulterior:

\section{Revista Brasileira de Direito Internacional | e-ISSN: 2526-0219 | Encontro Virtual | \\ v. 7 | n. 2 | p. 01 - 15 | Jul/Dez. 2021.}


A manifestação de vontade - que opera às vezes como elemento acessório para a determinação da nacionalidade originária - é pressuposto indispensável da aquisição ulterior de outro vínculo patrial, mas deve apoiarse sobre fatos sociais indicativos da relação indivíduo-Estado.

No caso dos imigrantes tiroleses, com a unificação da Itália em 1860, para que estes continuassem com a nacionalidade Italiana ou Austríaca, a manifestação de vontade era pressuposto indispensável para manter ou alterar suas origens. No entanto, ao não optarem por uma nacionalidade e emigrarem para o Brasil, em tese, acabavam renunciando sua nacionalidade originária.

Segundo Motta (2021, p. 238), em tempos mais remotos era normal que os imigrantes se vinculassem juridicamente a um Estado novo, renunciando sua nacionalidade originária:

À época, e dado as restrições que se tinha quanto aos meios de transporte, em regra, quando o indivíduo saía de seu país em busca de novas oportunidades, de uma nova vida, de constituir novos laços, ele não tinha a intenção de regressar para sua pátria. Portanto, natural que o ato de se vincular juridicamente ao novo Estado fosse visto pelas autoridades e pela própria comunidade internacional como uma forma de se submeter definitivamente ao país que lhe acolheu, renunciando até mesmo às suas antigas origens.

Importante destacar que a legislação italiana garante no art. 4 a nacionalidade em decorrência da filiação, ou seja, o jus sanguinis:

De acordo com o artigo 4 do primeiro livro do Código Civil Italiano de 1865 , é cidadão italiano o filho de pai cidadão italiano. Essa é a base do princípio do jus sanguinis da cidadania italiana que, traduzido do latim para o português, significa direito de sangue, mas que, embora tenha esse nome, não é transmitido pelo sangue, e sim pela filiação (MANTESSO; FERREIRA; ZANINI, 2018, p. 132).

Deste modo, que a dificuldade dos descendentes de tiroleses e dos trentinos em conseguir a concessão do reconhecimento da nacionalidade italiana, se deve justamente porque seus ancestrais não manifestaram interesse em continuar com a nacionalidade de origem, sendo assim, não há como transferir uma nacionalidade anterior se ela não fora mantida.

Ao renunciarem, ou simplesmente não se identificarem sendo pertencentes a uma cultura originária, os imigrantes tiroleses aceitaram intrinsicamente a nacionalidade secundária, ou seja, a brasileira. 
Para Maués (2013, p. 652), quando o Estado reconhece seus nacionais e lhes concede direitos, em troca requer fidelidade, de modo que:

[...] a prática de atos pelo nacional que evidenciem o rompimento desse vínculo acarreta a perda da nacionalidade, prevista no atual regime constitucional em duas hipóteses: o cancelamento da naturalização decorrente de atividade nociva ao interesse nacional e a aquisição de outra nacionalidade.

Para tentar amenizar os impactos decorrentes da impossibilidade do reconhecimento dos descentes de tiroleses e trentinos como nacionais, o Parlamento italiano no ano de 2000, ao receber inúmeros pedidos reconsideração de nacionalidade italiana aos descendentes de tiroleses e trentinos, num ato de exceção, aprovou a Lei 379/2000 que concedia a nacionalidade italiana aos descendentes de italianos nas condições supracitadas (MANTESSO; FERREIRA; ZANINI, 2018, p. 45).

No entanto, a supracitada Lei tinha como critério temporal a validade de 5 anos que foi prorrogada posteriormente por mais 5 anos, ou seja, o reconhecimento da nacionalidade italiana por descendência aos trentinos vigorou entre os anos 2000 e 2010.

Administrativamente não há possibilidade no momento de qualquer reconhecimento de nacionalidade aos descendentes de trentinos ou tiroleses. No entanto já há processos judiciais na Itália que discutem uma possível discriminação territorial quanto a negativa administrativa, desta feita pretende-se criar uma jurisprudência capaz de abrir precedentes capazes de regulamentar a situação (PERON, 2020).

\section{CONSIDERAÇÕES FINAIS}

A partir do ano de 1870, o Brasil recebeu em seu território mais de um milhão de imigrantes advindos da Itália e regiões limítrofes em decorrência da crise política, socioeconômica e falta de qualidade de vida.

Em decorrência de conflitos políticos e delimitação territorial entre a Itália e a Áustria, muitos tiroleses e trentinos, ao chegarem ao Brasil, não possuíam uma nacionalidade definida. Essa ocorrência se deve ao fato que os habitantes das províncias do Tirol do Sul e Trento após a unificação da Itália em 1861 com a entrada em vigor do Tratado de SaintGermain, teriam direito a nacionalidade italiana, porém precisariam requerer a nacionalidade 
do país em que se encontrasse ou deveriam migrar para a Áustria se optassem por aquela nacionalidade.

O tratado estipulava que os habitantes daquelas províncias teriam o prazo de 10 (dez) anos para se manifestar e requerer a nacionalidade em questão. No entanto, neste mesmo período, muitos indivíduos imigraram para o Brasil sem ter regularizado sua situação com o país de origem (MANTESSO; FERREIRA; ZANINI, 2018, p. 45).

Os imigrantes do antigo Império Austro-húngaro por sua vez, que hoje seriam cidadãos italianos, foram obrigados a renunciar sua nacionalidade para poderem emigrar para a América, chegando em terras brasileiras como apátridas e adquirindo consequentemente a nacionalidade secundária.

Desta feita, não há como os descendentes de trentinos e tiroleses terem seus requerimentos de nacionalidade italiana reconhecidos, considerando que seus ancestrais não possuíam qualidade de Italianos, ou seja, não há como repassar uma nacionalidade que, de fato, não foi requerida pelo próprio ancestral.

Em decorrência do grande número de pedidos de reconhecimentos de nacionalidade italiana por descendentes trentinos, o Parlamento italiano no ano 2000 criou a Lei 379, com intuito de facilitar o reconhecimento da nacionalidade italiana, porém a supracitada lei teve seu período vigência limitado em 10 anos, ou seja, de 2000 até 2010.

A temática é complexa e a pesquisa não se esgota tão facilmente. Hodiernamente não se pode mais requerer tal reconhecimento de nacionalidade pela via administrativa, o que torna a via judicial uma possibilidade.

\section{REFERÊNCIAS}

ACQUAVIVA, Marcus Claudio. Teoria geral do Estado. São Paulo: Saraiva, 2000.

ALTMAYER, Everton. Do que sou descendente: de tiroleses! Circolo Trentino di São Paulo, 2008. Disponível em: https://circolotrentinocaxias.com.br/_media/67f76_pequenaintroducao-sobre-nossas-origens-trentinas.pdf. Acesso em: 19 set. 2021.

ALTMAYER, Everton. Trento no Tirol. Tiroleses no Brasil, 19 ago. 2020. Disponível em: https://tiroleses.com.br/2020/08/19/trento-no-tirol/. Acesso em: 19 set. 2021.

ARRABAL, Alejandro Knaesel. Propriedade intelectual, inovação e complexidade. Rio de Janeiro: Lumen Juris, 2017. 
BAUMANN, Zygmunt. Globalização: as consequências humanas. Tradução Marcus Penchel. Rio de Janeiro: Zahar, 2021.

BERTONHA, João Fábio. O fascismo e os imigrantes italianos no brasil. Porto Alegre: Edipucrs, 2001.

CAMPOS, Yussef Daibert Salomão de. A Constituinte e a Constituição como instâncias do patrimônio cultural. Locus: Revista de História, v. 24, n. 2, 2018. Disponível em: Acesso https://doi.org/10.34019/2594-8296.2018.v24.20882 em: 18. set. 2021.

CORRÊA, Marcelo Armellini. O monumento aos tiroleses: a identidade dos imigrantes trentinos e seus descendentes no contexto do centenário da imigração italiana no rio grande do sul. XII Encontro Estadual de História Ampuh/Rs: História, verdade e ética, São Leopoldo, v. 1, n. 1, p. 1-12, 11 ago. 2014. Semestral. Disponível em: http://eeh2014 .anpuh-rs.org.br/resources/anais/30/1404771603_ARQUIVO_Monumentoaostiroleses.pdf. Acesso em: 19 set. 2021.

CORRÊA, Marcelo Armellini. Os imigrantes trentinos em Caxias do Sul (RS) e em Piracicaba (SP): um estudo comparativo. XIV Encontro Estadual de História Ampuh/Rs: História, verdade e ética, São Leopoldo. Disponível em: http://www.eeh2018.anpuhrs.org.br/resources/anais/8/1530308900_ARQUIVO_Osimigra

ntestrentinosemCaxiasdoSul(RS)eemPiracicaba(SP)umestudocomparativo.pdf. Acesso em: 19 set. 2021.

COSTA, Sérgio. Imigração no Brasil e na Alemanha: contextos, conceitos, convergências. Ciências Sociais Unisinos, [s. l], v. 44, n. 2, p. 1-168, 28 maio 2008. Semestral. Disponível em: http://revistas.unisinos.br/index.php/ciencias_sociais/article/view/5272/ 2526. Acesso em: 27 set. 2021.

DALBOSCO, Missael. O trauma da divisão do Tirol. Tiroleses no Brasil, 16 maio 2016. Disponível em: https://tiroleses.com.br/2016/05/16/o-trauma-da-divisao-do-tirol/. Acesso em: 19 set. 2021.

DECLARAÇÃO UNIVERSAL DOS DIREITOS HUMANOS. Assembleia Geral das Nações Unidas em Paris. 10 dez. 1948. Disponível em: https://www. ohchr.org/en/udhr/documents/udhr_translations/por.pdf. Acesso em: 19 set. 2021.

FRAGA, Andrey José Taffner; KEGEL, Patrícia Luiza. Reconhecimento da nacionalidade italiana aos descendentes de imigrantes trentinos no Brasil. In: MENEZES, Wagner. Direito Internacional: anais do $9^{\circ}$ Congresso Brasileiro de Direito Internacional. ABDI: Brasília, 2011. p. 131-138.

GUERRA, Sidney. Curso de direito internacional público. 8 ed. São Paulo: Saraiva, 2014.

MANTESSO, Virginio; FERREIRA, Bárbara; ZANINI, Fernanda. Guia de pesquisa genealógica para cidadania italiana. São Paulo: Imigração Italiana, 2018. 
MAUÉS, Antônio Moreira. Comentário ao art. 12 in: CANOTTILHO, J.J. Gomes; MESNDES, Gilmar F.; SARLET, Ingo W.; STRECK, Lenio L. Comentários à Constituição do Brasil. São Paulo: Saraiva/Almedina, 2013.

MAZZUOLI, Valério de Oliveira. Curso de Direito Internacional Público. 6 ed. São Paulo: Editora Revista dos Tribunais, 2012.

MORIN, Edgar. Introdução ao pensamento complexo. 4. ed. Porto Alegre: Sulina, 2011.

MOTTA, Luciano de Campos Prado. Revista de Direito Brasileira | Florianópolis, SC | v. 28 | n. 11| p.233-258| Jan./Abr. 2021233Revista de Direito Brasileira. Uma análise crítica da perda da nacionalidade brasileira. Revista de Direito Brasileira, Florianópolis, v. 28, n. 11, p. 1438, jun. 2021. Semestral. Disponível em: https://www.indexlaw.org/ index.php/rdb/article/view/3928/5377. Acesso em: 26 set. 2021.

NASCIMENTO, José do; KLEIN, Eloisa. Imigração italiana e igreja católica: um estudo de caso em nova trento-sc. Revista Maiêutica: História, Indaial, v. 3, n. 1, p. 01-155, 17 ago. 2015. Semestral. Disponível em: https://189-016-006-142.asselvi.edu.br/index.php/ HID_EaD/article/view/1377/526. Acesso em: 19 set. 2021.

PERON, Desiderio. Trentinos: Advogado anuncia que vai ajuizar ações de graça em busca de jurisprudência. Já existe ação na Justiça italiana à espera de decisão. 2020. Disponível em: https://www.insieme.com.br/pb/trentinos-advogado-anuncia-que-vai-ajuizaracoes-de-graca-em-busca-de-jurisprudencia-favoravel-mas-ja-existe-acao-correndo-najustica-italiana-a-espera-de-decisao/. Acesso em: 26 set. 2021.

REZEK, Francisco. Direito internacional público. 17. ed. São Paulo: Saraiva, 2018. 